\title{
Risks of Climate Change and Credit Institution Stress Tests*
}

\author{
Eszter Boros
}

Climate change is one of the greatest challenges of our time, even in the short term, and financial institutions will not escape its economic effects either. Focusing on the key players of the Hungarian financing model, i.e. commercial banks, the essay reviews how the risks associated with climate change can be assessed in the context of stress tests. To do this, it considers the most recent literature on the topic and aspects that have emerged in analyst practice. The discussion of the connected issues of this special stress testing process contributes to developing the framework of domestic bank climate stress tests, to identifying the most important challenges, and it provides guidelines for their management. The most significant revealed difficulties are the accurate capturing of climate shocks and identifying their macroeconomic channels. In addition, the transformation of standard banking risk models may also require significant work.

Journal of Economic Literature (JEL) codes: C51, C58, G17, G21, Q56

Keywords: sustainable finance, climate change, carbon neutral transition, stress test, risk management

\section{Introduction}

Today, climate change has also become an important topic for central banks, supervisory authorities and financial markets. The Bank of England (BoE), the European Central Bank (ECB), the US Federal Reserve (Fed) and other organisations are also emphasising the extent of the threat to humanity and the role of the financial intermediary system in tackling the problem. Christine Lagarde, former head of the International Monetary Fund (IMF) and current head of the ECB, drew attention to the risks of postponing climate actions even before the new boost for the global climate movement. In her indicative words, "unless we take action on climate change, future generations will be roasted, toasted, fried and grilled" (quoted by Marshall 2014: 59). Similar statements have been heard by the public in recent years from Mark Carney, former BoE governor, who described climate change

\footnotetext{
* The papers in this issue contain the views of the authors which are not necessarily the same as the official views of the Magyar Nemzeti Bank.
}

Eszter Boros is an Expert at the Magyar Nemzeti Bank. Email: borosesz@mnb.hu

The Hungarian manuscript was received on 25 May 2020.

DOI: http://doi.org/10.33893/FER.19.4.107131 
as "a tragedy of the horizon". By this, he referred to the common dilemma where the present motivations are not in line with socio-economic outcomes that would be optimal in the long run. ${ }^{1}$ Nevertheless, climate change is not just a possibility of a future catastrophe: more and more people are pointing out that it will have serious effects even in the short term. This may be particularly true for financial markets, as the assets involved can be repriced quickly (Rudebusch 2019). More broadly, we are already seeing more and more phenomena today that are "byproducts" of the carbon-based economy aimed at infinite growth. These include weather emergencies, but also threats related to large-scale livestock farming and global tourism, such as the increased risk of pandemics (cf. Harari 2015; Staden 2020).

It is no coincidence that the main common thread in the statements of key financial managers is time horizon. Namely, climate change is a complex process, whose understanding requires a long time, while risk management must already be considered in the short term. Climatic events tend to unfold in full over decades, causing great uncertainty in the present. However, many think the measures taken to control the harmful processes are already late, and they call for immediate drastic action to achieve the so-called Paris climate targets (see $U N^{2}, B o E 2019$ ).

The Paris Climate Agreement (UN 2015) set the goal that the increase in the average temperature of the Earth must not reach $+2^{\circ} \mathrm{C}$ compared to temperatures experienced before the industrial revolution. To this end, the 95 signatory countries and the European Union have made significant commitments to limit greenhouse gas (GHG) emissions. This is because in the absence of such measures, the coming decades could bring significant warming. According to the scenarios of the United Nations International Panel on Climate Change (IPCC), failure to take appropriate action could lead to a rise in temperature of more than $+4^{\circ} \mathrm{C}$ by the end of the century (IPCC 2013). Figure 1 shows the warming scenarios outlined by the IPCC that correspond to certain greenhouse gas concentration trajectories (representative concentration pathways, RCPs). To achieve lower temperature pathways, humanity must significantly reduce its $\mathrm{CO}_{2}$ emissions (decarbonisation). For lack of this, a rise in average temperature may result in an increase in heat-related deaths, vegetation transformation, and changes in agricultural yields, to name just a few possible consequences (Burke et al. 2015; UNEPFI 2018a; Gallic - Vermandel 2019).

\footnotetext{
${ }^{1}$ Breaking the Tragedy of the Horizon - Climate Change and Financial Stability. Speech by the Governor of the Bank of England on 29 September 2015. https://www.bankofengland.co.uk/speech/2015/breaking-thetragedy-of-the-horizon-climate-change-and-financial-stability. Downloaded: 2 April 2020.

${ }^{2}$ Climate Change. https://www.un.org/en/sections/issues-depth/climate-change/. Downloaded: 2 April 2020.
} 


\section{Figure 1}

Possible scenarios for global average surface temperature increase (increase compared to pre-industrial temperatures)

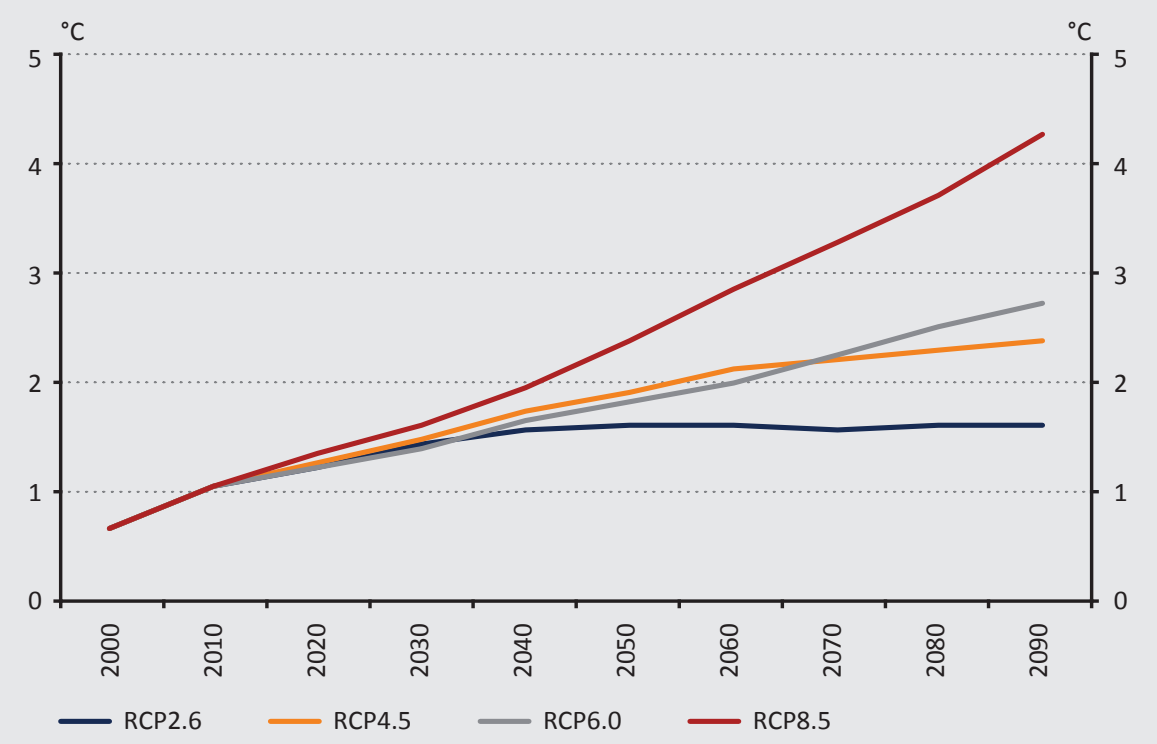

Note: RCP (representative concentration pathway): greenhouse gas concentration trajectories adopted by the IPCC. The figure shows the corresponding expected changes in temperature.

Source: Plotted based on IPCC (2013) data

The decarbonisation process also affects banks, in fact, they are key players in it. This is because credit institutions ${ }^{3}$ indirectly have a significant impact on the state of our planet through their business decisions. Financed companies, investments, projects and real estates can be very different from an environmental perspective (UNEPFI 2018b). They differ in their emissions (carbon intensity) both in terms of their own economic activity/operation and the supply chain that covers them. Therefore the exposures in banks' books carry different risks from a climate perspective too: they may react differently to environmental, environmental policy and technological developments. Some financed clients (such as agricultural businesses) may be more vulnerable to weather events. Other debtors may be more sensitive to the regulatory and technological process of the transition to a carbon-neutral economy (fossil fuel power plants, manufacturers of internal combustion engines and vehicles, etc.). Thus through their clients, banks also face the effects of climate change, which, similar to other risks, can jeopardise their profitability and capital position, and thereby ultimately the stability of the financial intermediary system (NGFS 2019; Feyen et al. 2020). To ensure sound banking it is now clear that credit institutions

\footnotetext{
${ }^{3}$ In the essay, the terms "credit institution" and "bank" are used interchangeably.
} 
must also take these factors into account in their risk management. ${ }^{4}$ In addition to the general principles of prudent operation, the consideration of climate change effects is already envisaged by international recommendations (Financial Stability Board, Task Force on Climate Related Financial Disclosures, FSB - TCFD 2017). In Hungary, the measures identified by the National Energy and Climate Plan (NECP) (ITM 2020) and the financial stability focus points of the Central Bank of Hungary (Magyar Nemzeti Bank, MNB) (MNB 2019) also encourage credit institutions to prepare to identify the vulnerabilities that may emerge during decarbonisation.

However, it is a great challenge for banks to capture and analyse these "unusual" risk factors. In recent years, a number of research projects as well as pioneering work and initiatives of banks and the central banks have been carried out to assess the effects of climate change on credit institutions and develop the necessary toolbox (e.g. BoE 2018; Vermeulen et al. 2018; MNB 2019). Even so, the topic is still considered new to most financial institutions in the world, including Hungarian banks. The aim of this essay is to contribute to the development of Hungarian bank climate stress testing practice by providing a comprehensive explanation of a possible framework. It is based on the widely used structure of credit institution stress tests and determines the main aspects and challenges arising from the application of climate shocks. The article is structured as follows: Chapter 2 discusses the key concepts and basic considerations required for climate stress testing, and then outlines the overall structure of the stress test. Chapter 3 deals with the building blocks of this, focusing on integrating climate change. Chapter 4 summarises the conclusions.

\section{Bank stress tests and climate change}

The bank stress test is a complex quantitative analysis to assess how credit institutions would withstand severe economic downturns and shocks (Quagliariello 2009; Borio et al. 2014). ${ }^{5}$ Over the applied time horizon, the expected trajectory of bank exposures, profitability and own funds according to a given scenario can be simulated by means, and with the assumptions, of the stress test.

\footnotetext{
${ }^{4}$ Of course, economic processes related to climate change also carry business opportunities, and banks can actively shape their portfolios to seize these opportunities by selecting the right companies. This enables them to have a broader impact: by financing climate-friendly investments and companies, they can make their own contribution to mitigating climate change. An analysis of these strategies and effects would require dedicated research - this essay focuses on measuring risks.

${ }^{5}$ The stress test can be macro-level (covering the entire banking system) or it can examine a single bank (Quagliariello 2009). The former types of test are typically performed by central banks and other systemic risk assessment organisations, while individual-level tests are typically carried out by supervisory bodies and the credit institutions themselves. Macro-level tests may also be able to provide a forecast for individual banks. From the point of view of the essay it does not matter who performs the stress test, it should only be noted that we use stress tests that are (also) suitable for quantifying individual banking effects.
} 
Even this brief definition reflects why the essay chooses stress tests from a wide range of risk measurement tools to examine climate factors. Namely, stress tests allow for a complex analysis of a bank's situation, i.e. they primarily represent a framework, a comprehensive "apparatus" into which several specific models fit (or can be incorporated). In addition, the method has been developed precisely to examine different future scenarios, so by its design and purpose it may be suitable for tracking the trajectories of climate change. As stress testing has been widespread in the practice of banks, central banks and supervisory authorities since the 2007-2008 crisis, and even regulations based on Basel standards require its regular application, institutions do not need to develop a new tool for assessing climate risks. It is enough to adjust existing approaches, although this is a major challenge - precisely due to the particularities of climate change.

Climate change differs significantly from the most commonly modelled "traditional" shocks. Stress tests usually start from economic shocks for which experience and data are already available. Economists can determine their characteristics, the channels through which they ripple into the economy (such "usual" shocks can include, for example, an increase in oil prices, a tax increase, a shift in demand). The occurrence and course of these can naturally be predicted to a limited extent only (cf. Taleb 2007), but past experience can still reduce the uncertainty: they turn it into a quantifiable risk. For the sake of simplicity, the dangers of climate change are also referred to as "risk", but the phenomenon in fact carries much more uncertainty than normal. Atmospheric and environmental impacts are extremely complex and have a very multi-faceted correlation with human activities. Moreover, interactions tend to unfold usually only over a longer period. Due to all this, today we still have relatively little knowledge and experience about the transformation of ecosystems, and translating the existing physical-ecological knowledge into the language of economics and finance also remains a problem. So intense thinking on climate stress tests is currently under way among financial institutions around the world and their stakeholders.

The recognition that climate risks can basically be divided into two groups (UNEPFI 2018a, 2018b; NGFS 2019) helps to capture them. Physical risks arise from the underlying process itself, from the atmospheric and environmental transformation. Thus, they represent the risk of losses caused by phenomena attributable to climate change (such as climatic disasters). These may directly affect the facilities and employees of banks, but the damage to the financed economic entities endangering their solvency is of even greater importance. A more precise definition of the physical risks to a geographical area requires primarily scientific or sectoral (such as agricultural) expertise. 
Another large group of climate risks are called transition risks. This is not about climate change itself, but about the effects of the measures taken to prevent and mitigate it. Transition risks therefore include shocks arising from the technological and policy/regulatory transition to a low-carbon economy. The transformation of the fossil economy requires multiple government interventions (taxes, subsidies, government purchases, etc.) and technological change that could, at least in the short term, adversely affect a significant number of economic actors. The most obvious examples are coal mines, oil producers, fossil energy producers, vehicle manufacturers and airlines, but in reality, through the amounts of $\mathrm{CO}_{2}$ embodied in products and services, the entirety of modern economies are involved in the process. (It is precisely this $\mathrm{CO}_{2}$ amount that could be the basis for determining vulnerability in modelling, see BlackRock 2015; Vermeulen et al. 2018.) The involvement of banks primarily depends on the composition of their portfolios. Knowledge of the region's/country's climate strategies, development plans and technological trends are most needed to specify transition risks. At the same time, despite the environmental commitments already made by governments and companies, the decarbonisation transition may not necessarily take place, or it may take place in a disorderly and uncontrolled manner. A delayed, disorderly transition is obviously much more unpredictable and entails greater shocks: fractures such as a panic repricing of assets, a rapid decline in the market capitalisation of some companies, or even state bankruptcies (Battiston - Monasterolo 2019). Transition and physical risks certainly correlate: the later and the more disorderly the transition attempt, the greater the chance of unfavourable temperature outcomes.

The demarcation of the two types of risk helps to choose the time horizon of the analysis. As already emphasised, one of the main challenges in integrating climate change into bank stress tests is the time horizon. "Normal" stress tests used in bank risk management typically look at shorter periods (3-5 years) as they are designed to provide information about the direct course of a shock. Relying on this toolbox, a significant proportion of existing climate stress tests continue to use the shorter horizon (for example Vermeulen et al. 2018; Stamate - Tatarici 2019). However, some approaches under development (BoE 2019; NGFS 2019) intend to take a longterm horizon into account, up to several decades, in line with the dynamics of weather events and the transition process.

Figure 2 illustrates a possible demarcation between the short and long term as two options for analysis. In the case of a shorter horizon, we can model the effect of a specific shock in line with the established stress testing practice. To do this, one or a few events must be selected from the transition/physical risks. These shocks can be translated relatively easily into the language of standard macroeconomics 
(for example: cost shock, demand shock, supply shock). (Scenarios are discussed in detail in the next chapter.) The ease of short-term analysis is that it is sufficient to consider the chosen shock alone: it is not necessary to incorporate climate change as a complex phenomenon. The model basically examines the impact of the event on the economy - through the identified channels - and then on the balance sheets of individual banks in the shorter period considered. In the case of a long-term analysis, however, we can no longer ignore the many different channels of and interactions between the processes that can be attributed to climate change. At this point, we already need pathways that, looking ahead, describe the changes in certain key variables (such as GHG emissions, temperature, precipitation, energy consumption, policy and social indicators). Incorporating expectations related to the processes can also be an important requirement. Producing or purchasing the scenarios from scenario providers and their use requires significant expertise and resources.

\section{Figure 2}

Shorter- and longer-term climate stress tests

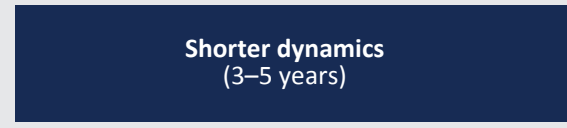

One or a few shocks, direct adaptation of the economy and banks

Transition risks:

Technological shock

(e.g. market breakthrough of

low carbon technologies)

and/or Policy shock

(especially discretionary measures,

e.g. levying a tax on carbon emission)

Physical risks:

Extreme weather events

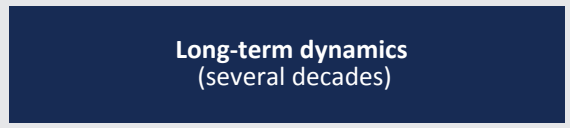

Complex process of climate change and economic and social corollaries

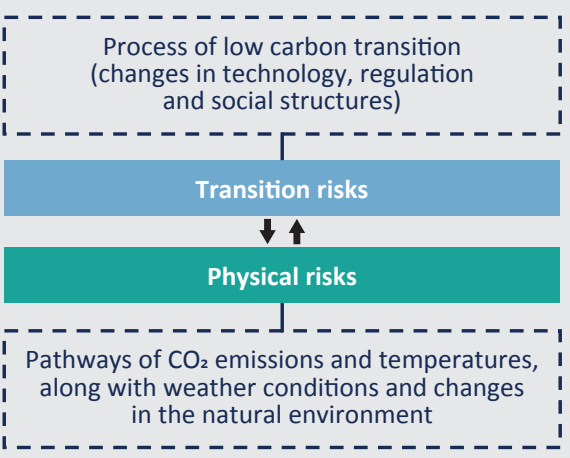

Interlinkages cannot be ignored 
The general structure of bank stress tests may be relevant for both time horizons. This structure is shown in Figure 3 based on the ECB's methodological description (Henry - Kok 2013) and Borio et al. (2014). The figure indicates the key elements for which climate considerations are particularly relevant. Scenarios (1), which contain the exogenous changes (shocks) to be examined in different variations represent the starting point of the stress test. The first step of the modelling phase (2) is usually the analysis of macroeconomic and macro-financial effects, which requires a macroeconomic model suitable for the purpose and focus $(2 a)$. The different financial risk models for selected bank exposures $(2 b)$ can "translate" the outcomes of the macroeconomic model to individual banking and portfolio levels. In possession of these, the key data characterising the operation of the credit institution (balance sheet and income statement items) can be forecast for certain points and sections of the time horizon in different scenarios (2c). Importantly, this is not a general prognosis in the classic sense, but a forecast valid in each possible scenario. The main objective is to outline the bank's profitability and, in that context, the capital position (capital adequacy) (3). Namely, this will show whether the credit institution is able to remain solvent under different scenarios; whether its capital adequacy will meet minimum regulatory requirements. The most advanced stress tests also capture spillover effects and feedback (4), but their modelling is still typically less mature in the context of credit institution stress tests (Borio et al. 2014). The development and operation of short-horizon climate stress tests reaching first-round impacts on capital can already be considered the best practice among Hungarian banks, relying on existing stress testing methodologies. (Nevertheless, long-term climate stress tests are a much greater challenge even on the international scene.) The elements of the framework outlined here build closely on one another, and it is impossible to specify them without rethinking the entire modelling process. The individual components and the incorporation of climate considerations are discussed in detail in the next Chapter. ${ }^{6}$

\footnotetext{
${ }^{6}$ The aim of this essay is not to delve into the individual building blocks, but to outline the links present throughout the stress test, the role of the components, the key issues, and aspects arising from the particularities of climate change.
} 


\section{Figure 3}

Structure of bank stress tests and incorporating climate risks

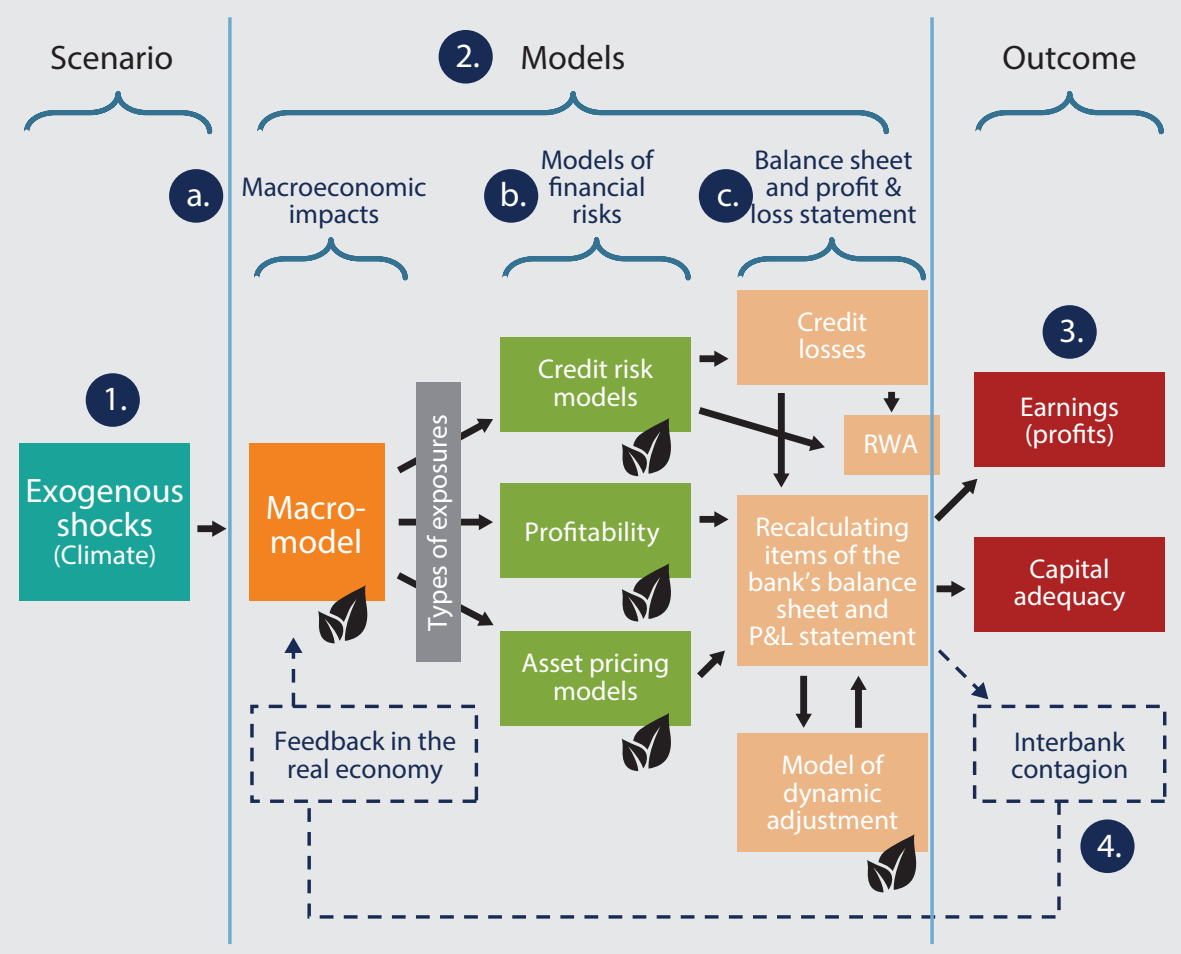

Note: Letter icons indicate climate-specific changes and the need to consider related aspects.

Source: Plotted based on Henry - Kok (2013) and Borio et al. (2014)

\section{Building blocks of climate stress tests: shocks and risk models}

\subsection{Shocks (scenarios)}

The stress test becomes a climate stress test because the underlying scenarios variations in shifts in the economy - are related to climate change. Due to their purpose, stress tests primarily examine adverse shocks, but this shall not preclude positive effects emerging in some sectors or over time in the economy as a whole. The chosen shocks must be significant in size but also plausible (Quagliariello 2009). Therefore, scenarios need to be defined in a way that their occurrence is realistically conceivable. If we perform an analysis for a specific, shorter-term shock (Figure 2), the climate protection strategies, emission reduction commitments and action plans of each government are available as guidance for identifying the 
environmental and economic policy interventions expected in the near future. In Hungary, such a document is currently the afore-mentioned NECP (2020), which mainly envisages investments, subsidies, tax and regulatory changes related to energy efficiency and zero-emission technologies. Technology shocks can be derived primarily from changes in the specific costs of decarbonisation solutions (such as renewables), which affect their spread. These shocks are disruptive in terms of their immediate impact; thus, they radically transform the energy production that drives the economy and the positions of many market players (cf. Di Silvestre 2018).

As an example of shorter-term scenarios, it is worth noting that the five-year stress test of the Dutch central bank (Vermeulen et al. 2018) combines cases of an economic policy and a technological change, thus forming four scenarios (Figure 4).

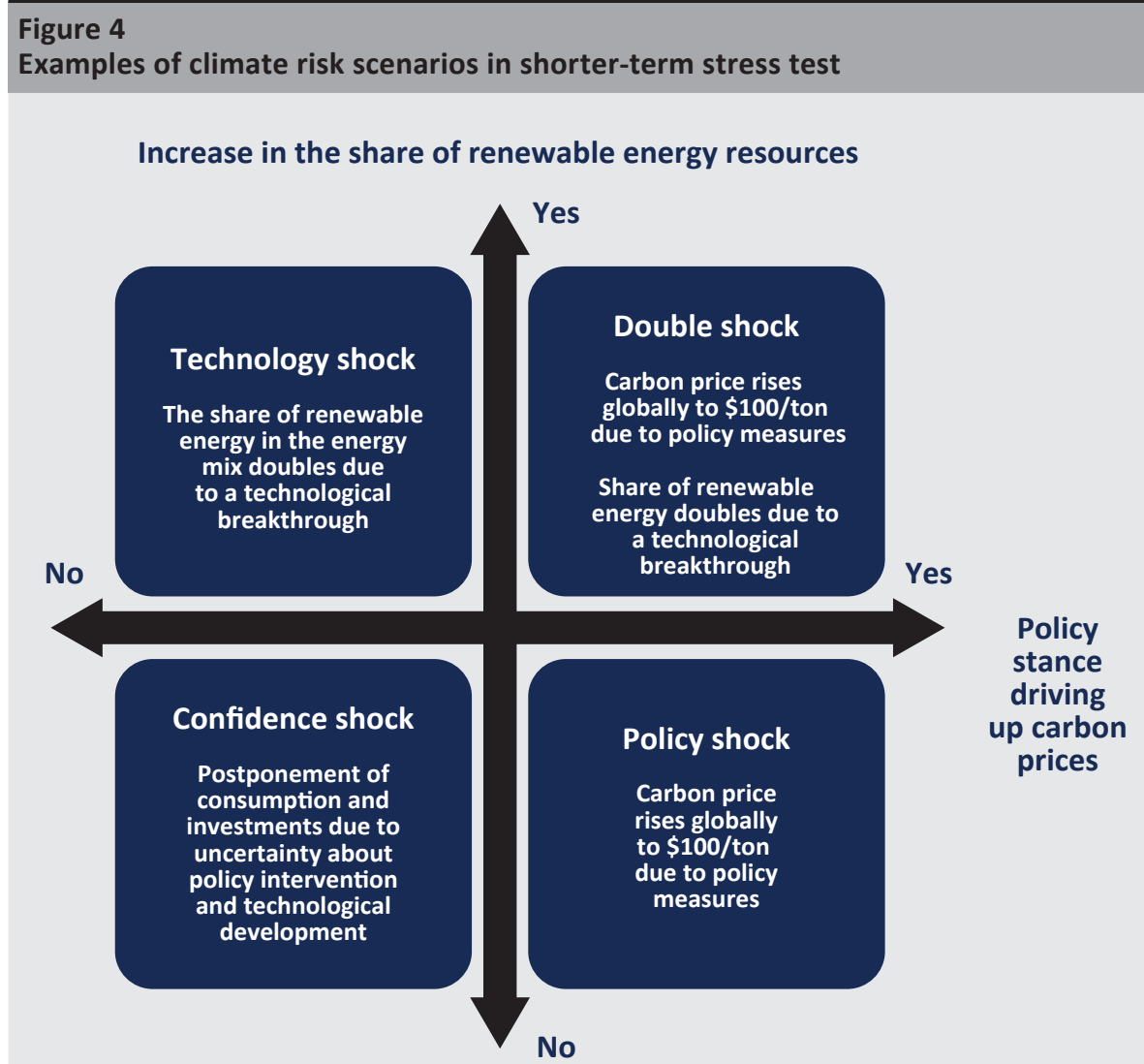


Economic policy intervention means the introduction of stringent measures that result in increasing GHG-emission costs (for example, the market price of traded carbon allowances affecting global emissions rises to 100 USD/ton). And the technological change is the breakthrough of carbon-neutral solutions with minimal emissions (renewable energy sources). In the case of a "double shock" (upper right case), both the quota price and the rate of renewables rise. This is undoubtedly the most favourable scenario for stopping climate change, however, it predicts a significant economic shock. The two shocks can also be examined separately (upper left and lower right cases). Finally, the lack of environmental policy measures and technological breakthrough represent the least promising scenario in terms of global warming (bottom left corner). The authors call this a "confidence shock". The loss of confidence of economic actors is due to failure to take the actions necessary to stop climate change. This is because huge uncertainty is created by the fact that a higher chance of a future climate disaster also involves a higher probability of a disorderly transition (i.e. late and hasty intervention). This results in the postponement of investments and consumption and in an economic downturn, even in the shorter horizon.

In addition to the scenarios, a baseline scenario is always needed as a benchmark, which provides a forecast valid in the absence of shocks. This can rely on official forecasts from international or national organisations or on expectations in accordance with the bank's own models. However, as the "confidence shock" of the Dutch example suggests, there is limited room for using the business-as-usual baseline when considering climate change. This is especially true for longer-term analyses. Namely, according to scientific consensus, global warming is a process on Earth still under way that we cannot ignore in the absence of appropriate measures. Thus the baseline scenario is actually provided by the unfolding of adverse climaticweather processes, or if you prefer, the $+4^{\circ} \mathrm{C}$ temperature rise by 2090 shown in Figure 1.

This approach is also reflected in long-term climate stress testing efforts. Among the high-level scenarios of NGFS (an initiative bringing together the world's leading central banks and supervisory authorities), a scenario corresponding to an uncontrolled climate catastrophe appears (Figure 5; "too little, too late"). This set of four high-level scenarios provides a good starting point for long-term analysis, as it addresses the unfolding of physical and transition risks together, in conjunction with one another. In the case of "too little, too late", panic-like, delayed measures cause further economic shocks, while they are no longer able to prevent adverse physical effects. Hyne et al. (2019) suggest that this scenario deserves the most attention, as the primary purpose of stress testing is to assess the realistically worstcase scenario. The European Systemic Risk Board (ESRB) also points out that the

\footnotetext{
${ }^{7}$ Network for Greening the Financial System
} 
occurrence of this scenario will, over time and as emissions continue to rise, become increasingly important from a financial systemic risk perspective too (ESRB 2016). The other three scenarios on Figure 5 contain less drastic outcomes compared to the hasty, missed adaptation, although these also include the "greenhouse Earth". This is just as destructive from an environmental point of view (as harmful warming still occurs), "only" the economy is not hit by disruptive measures. Namely, at this point, the international community will be permanently stuck at the level of current commitments, the world will not deviate significantly from the fossil mode of operation; thus climate change will ultimately unfold. This scenario typically reflects deterrence from making sacrifices, and as a consequence, no further ambitious actions will be taken. Currently, there are several signs that we are moving on this trajectory: emission reduction commitments are being made and actions taken worldwide, but these are not considered by many to be sufficient to stop severe warming. ${ }^{8}$ On the contrary, scenarios that meet climate targets (i.e. a drastic and orderly transition) are more favourable, although there is a difference here too: a drastic (successful, but abrupt) transition envisages a serious economic shock.

The two types of scenarios (short-term and long-term) illustrated on Figures 4 and 5 are filled with content by the stress testing institution, taking into account its own operating environment, business strategy and exposures. However, climate change is an unknown "terrain" for credit institutions; it falls outside of the scope of regularly analysed economic and financial risks, therefore (external) expert support may be needed even for the shorter time horizon. Today, many scientific institutes, organisations and consulting firms (hereinafter collectively referred to as: scenario providers) offer solutions. In addition, the fact that central banks, supervisory authorities and international organisations are also striving to create uniform, accessible sets of scenarios (e.g. $2^{\circ}$ Investing Initiative 2018; BoE 2019) is a positive development. In the future, these uniform scenarios handed over to banks may be the basis for climate stress tests. But even then, it is important that credit institutions make their own assessments regarding the range of physical and transition risks that are most relevant to them.

\footnotetext{
${ }^{8}$ The future may well hold rapid and dramatic measures, and with that we can even pass into the "too little, too late" scenario. At the same time, recent international summits have raised doubts as to whether further large-scale, joint international action would be taken.
} 


\section{Figure 5}

Baseline scenarios for climate change and human intervention in long-term stress tests

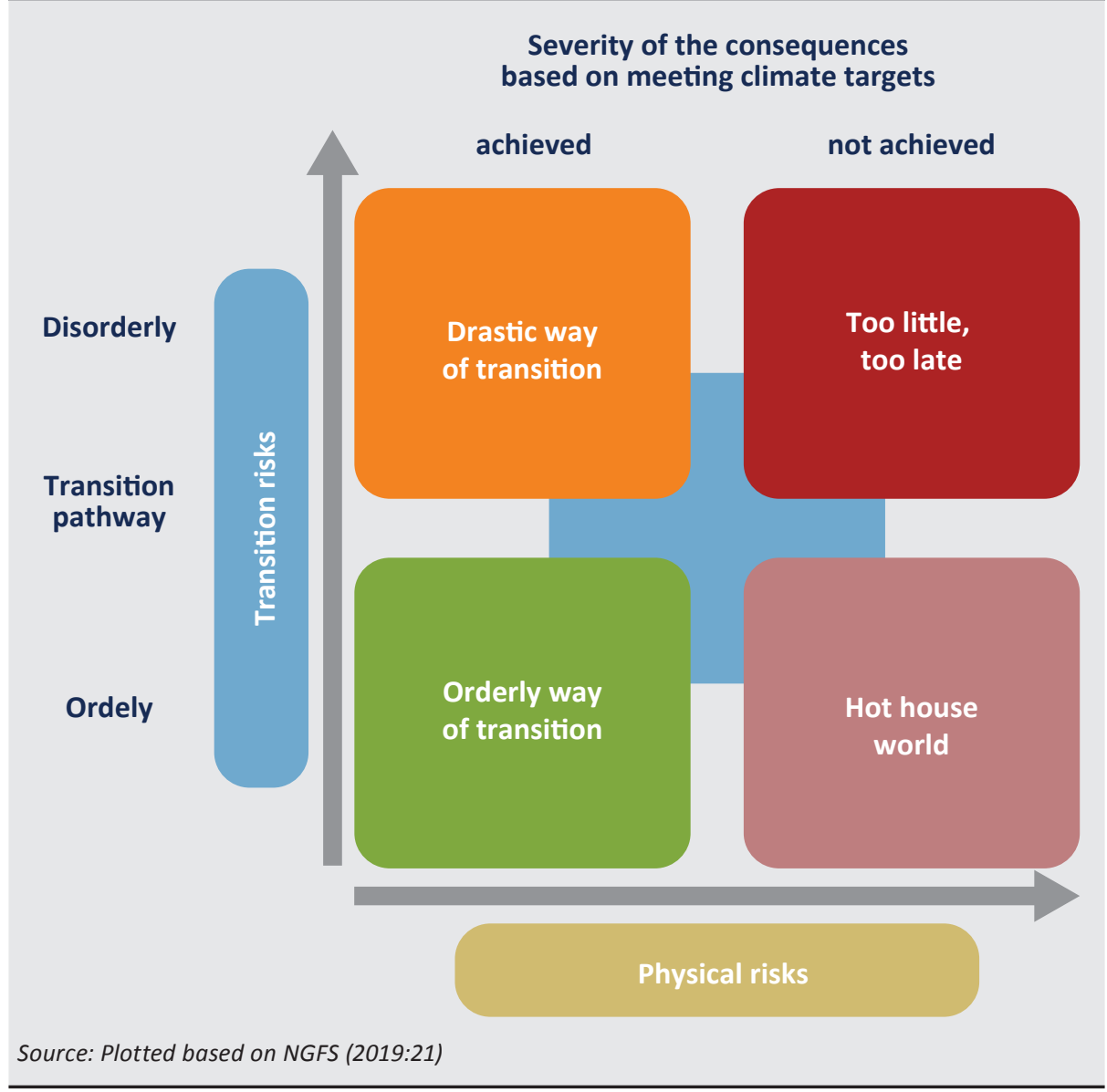

A crucial aspect in developing scenarios is that the macroeconomic model available should be able to integrate the information (Figure $32 a$ ). More generally, the scenarios and the macroeconomic model should be chosen together, both interlinked. (As already mentioned, all elements of the process are closely linked.) In the relationship between scenarios and the macroeconomic model, the provision of transmission channels is the crucial point, which can even become the biggest challenge of the entire climate stress testing. The credit institution must determine the sections of the economy (actors, sectors, etc.) primarily affected by the physical and/or transition events to be analysed and the way this initial effect manifests. In a shorter-term analysis, where the focus is on the course of one or a few specific shocks, this information is somewhat easier to specify and translate into the language of macroeconomics (modelling). 
However, even in such cases, the connection with the macroeconomic model is made difficult by the fact that data on identical historical events and situations are typically not available to determine the magnitude of the initial effects. This problem can be partially resolved by identifying similar shocks, using data and assumptions available in literature, and by means of expert estimation. (However, the applicability of historical data is limited as the future magnitude of impacts naturally may differ significantly from experience thus far.) Scenario providers' scenarios include related assumptions, and the provider frequently even carries out the macroeconomic modelling. When it comes to the long-term complex analysis of climate and socio-economic pathways, it is even more necessary to create a close connection and a unified framework for scenario building and macroeconomic modelling.

\subsection{Macroeconomic model}

Thus although macroeconomic effects often appear as part of scenarios, it is worth separately addressing the models that produce them (Figure $32 a$ ). Based on their purpose, Blanchard (2018) distinguishes five general types of macroeconomic model: basic theoretical models, dynamic stochastic general equilibrium (DSGE) models, policy models, "toy models" (tools of the simplest macroeconomic illustration), and forecasting XXXX models. Of all these, policy and forecasting models are the closest to the objectives of climate stress tests. Policy models are designed to analyse specific economic policy problems, the dynamic impact measurement of the intervention alternatives, their main goal being to explore the patterns. ${ }^{9}$ Forecasting models have obviously one goal in mind: to produce the best forecasts. These are primarily statistical-econometric models and their main questions are related to fitting. There is of course no sharp boundary between the individual model types, but grouping helps to determine the tools needed for climate stress testing, thus in particular, to assess the suitability of credit institutions' internal macroeconomic models. In climate stress tests, especially in the longer term, a combination of the policy-type and forecasting model approach may provide the most useful results.

One of the model families frequently used by scenario providers is called integrated assessment models (IAM). These are not explicitly macroeconomic models, but capture the correlations between energy consumption, climate/environment, demography, and economic activity (IPCC 2013; Farmer et al. 2015; Hare et al. 2018). The integrating economic elements are usually based on the principles of general equilibrium and market efficiency. This is because IAM models combine simplified models of the considered spheres and, first and foremost, seek to create

\footnotetext{
${ }^{9}$ These models may also be DSGE-based, "but their theoretical structure must by necessity be looser than for DSGE," thus "leading to much more complex overall dynamics than a tight theoretical model can hope to capture" (Blanchard 2018:53).
} 
interactions. Of the three main components (energy, climate, socio-economic system) they rather break only the first down into more detail, global and regional energy systems. The overall goal is to forecast the consequences and outcomes of different climate policies. However, Farmer et al. (2015) point out that IAM models can be subject to a number of criticisms: they do not adequately address the significant uncertainty of climate change; they use a high degree of simplification (representative household, company); their functions determining environmental damage are highly stylised; and they are less able to capture technological progress in a complex way. These criticisms mainly concern the economic content of IAMs, which also influences the reality of the energy consumption, emission and environmental trajectories provided by the models. Therefore, and due to the narrow range of macroeconomic outputs, IAM models can mostly play an intermediate, "intermediary" role between climate scenarios and the main macroeconomic model, for example in producing some input trajectories needed for the latter.

In the economic component of IAMs and also in other climate modelling applications, the so-called computable general equilibrium models (CGE) appear. These, as mentioned above, start from micro-level optimising behaviour. They are typically static, aimed at determining the equilibrium price and quantity, and thus allow for comparative static analyses (aimed at comparing equilibrium situations). ${ }^{10}$ Assumptions of CGE models concerning the financial system are usually unrealistic (Pollitt-Mercure 2018). The cited authors point out that in the traditional approach of the CGE, climate protection policies almost always have negative economic consequences (GDP decline). This is because green investments have a crowdingout effect on other sectors of the economy.

Pollitt and Mercure (2018) emphasise the advantages of non-equilibrium, empirical (macro-econometric) models over CGE. These models have long been established tools for economic forecasting and combine both theoretical and data-driven correlations. ${ }^{11}$ They do not assume the optimising behaviour and perfect rationality of economic actors, instead they use behavioural equations "read" from the data by means of econometric tools. The long-term equilibrium of the economy is also not a baseline. Macro-econometric models focusing on climate change have also been created in recent decades. One of them is the E3ME model, in whose name the $3 \mathrm{E}$ refers to the relationship between the economy, energy systems and the

${ }^{10}$ CGE models have a number of features in common with DSGE models treated as a distinct category by Blanchard (2018). The latter are dynamic (describe the economic fluctuations), but typically model the economy at a much more aggregate level compared to CGE models (See: Computable General Equilibrium Modelling: Introduction. Chief Economist Directorate, Scottish Government, published on 6 January 2016. https://www.gov.scot/publications/cge-modelling-introduction/. Downloaded: 21 April 2020).

${ }^{11}$ For the theoretical correlations the post-Keynesian background is typical, the main elements of which being the theory of efficient demand and endogenous money, the privileged role of uncertainty and expectations, and the consideration of income distribution and institutions (Horváth 2003). 
environment. The non-equilibrium nature of the model (potential for unused capacity) ensures that the steps of a climate-neutral transition can even entail positive GDP developments (Cambridge Econometrics 2019). The disadvantage of macro-econometric models similar to E3ME may be that they are extremely dataintensive and require reliable and long time series for a number of economic and environmental variables. ${ }^{12}$

For the next phase of the stress test - bank risk calculations - two essential features of the macroeconomic model need to be highlighted. On the one hand, it is important for the model to produce trajectories of as many macro variables as possible. The most basic, of course, are GDP and its components (consumption, investment, net exports), along with indicators for companies and households separately (disposable income of households, activity rate, unemployment, etc.), and inflation. At the same time, not only macroeconomic but also macro-financial variables are needed, such as different interest rates (points on yield curves) and exchange rates. In addition, it would be favourable for the model to provide information on financial stocks and flows too: in particular, financial savings, borrowing or net financial assets of households, corporate borrowing and/or the various consolidated ratios of the banking system. This also indicates the importance of the financial intermediary system appearing in the model under sufficiently realistic assumptions (e.g. endogenous money creation). However, it is most likely that the available solutions will only produce financial variables on a narrower scale. (Exceptions to this may be credit institutions' own internal macro-models.)

On the other hand, the next phases of stress testing require that macro-level outputs also be available in a proper industrial breakdown (Allen et al. 2020). Industries shall mean the sectors of economic activity. Namely, the industrial pathways carry important information about the vulnerabilities and risks of the financed companies in certain scenarios. Climate change-related shocks can manifest in different ways and to different extents, for example in vehicle manufacturing, mining or accounting and advisory services. However, we cannot expect a specifically detailed breakdown from these models, as their primary purpose is not to perform industrial analysis. For this reason, where applicable, it may be useful to use several industry-specific models (in a complementary manner). Additional climate-related delimitations can be introduced in the next phase of stress testing.

\subsection{Financial risk models}

In possession of the information on macroeconomic and industrial effects, the analysis of the specific situation of a bank can begin (components $2 b$ and $2 c$ of Figure 3). To do this, we must first decide which bank exposures to include in the stress test. Ideally, the test covers the entire operation of the bank and all its

\footnotetext{
12 There are certainly many other modelling approaches, which are not covered in the essay.
} 
exposures, as this is the only way to quantify the expected impacts on profitability and own funds fully and consistently. However, if necessary and depending on the available toolbox, a partial analysis is also conceivable: in the case of domestic commercial banks, highlighting the credit exposures (banking book) may be considered above all else. Then, component $2 b$ can rely on a narrower set of tools. The essay reviews issues of a wide range of exposures.

Mapping the entirety of banking operations and all the exposures requires a number of risk models, correlations and assumptions. These are already available to credit institutions for "normal" stress tests, at least for their normal time horizon. The toolbox for measuring and analysing credit risk, market risk, operational risks and profitability (and to a lesser extent liquidity risk) should be considered here. Applying these tools in the context of climate stress tests, however, raises a number of issues and amendment requirements. ${ }^{13}$

Credit risk is the risk of the non- or non-contractual performance of bank debtors. Credit risk models are aimed at assessing expected credit loss (ECL). This requires the determination of clients' probability of default (PD), exposure at default (EAD) and loss given default (LGD), the product of which gives the ECL. The calculation approach differs significantly for mass standard loans (retail, small business), and larger, individually considered loans (large corporate, project). Regardless of type, however, climate stress testing will definitely pose two significant challenges in modelling the components of ECL. One is the direct representation of vulnerability to climate change in the PD, and the other is the climate-based revaluation of collateral in LGD calculations.

The PD calculation is based on the collection of factors statistically related to non-payment (characteristics of the debtor and the transaction). As already mentioned, the PD of individual corporate clients is significantly affected from a climate perspective by their industry. Thus, it is advisable to include the macro variables broken down by industries into the PD factors. With granular data, it is also worth making a distinction between clients within industries based on their vulnerability. Thus in the energy sector for example, ceteris paribus there may be a higher PD for fossil fuel power plants, in line with the given scenario, and a lower one for solar power plants. ${ }^{14}$ The approach developed by the United Nations

${ }^{13}$ To assess liquidity, credit institutions usually perform dedicated liquidity stress tests. Many aspects of liquidity (e.g. daily liquidity, foreign exchange liquidity) are not the focus of stress tests focusing on capital adequacy, and this is especially true of complex climate stress tests to assess long-term effects. Liquidity risk is therefore not covered in this essay. Banking risks and their fundamental conceptual elements are further defined based on Walter (2016).

${ }^{14}$ The need for differentiation arises, inter alia, because the industrial breakdowns available for macromodelling are unlikely to carry sufficient climate-related information. Namely, the most commonly used classifications (NACE, in Hungary: TEÁOR) were not developed from this perspective or for this purpose (Battiston et al. 2017). In addition, even for climate classifications, companies with a mixed profile/strategy (such as a company producing both fossil fuel and electric vehicles) would pose a problem. 
Environment Programme and 16 contributing large banks (UNEPFI 2018b) is aimed exactly at this: it ranks actors in each industry according to the key risk factors in the scenarios (from low to high risk) and then diverts companies' PDs based on the classification. The basis for the vulnerability classification can be, for example, carbon intensity characteristic of industry subgroups (amount of $\mathrm{CO}_{2}$ incorporated per unit of output), and/or information derived from individual large enterprise strategies. There is certainly little or no historical data available to fit macro variables broken down by industry into the PD model (significance, coefficients, etc.) and to determine the PD deviation within the industry. Therefore the calibration may rely primarily on literature/expert estimates and internal information available for some large clients. In addition to identifying the initial macro channels, this represents another serious challenge to climate stress testing.

In the retail sector, the most critical "targets" of climate change and the carbonneutral transition are real estate, which, when used as collateral, mitigate the expected credit losses of banks. Properties with poor energy efficiency, with only fossil heating, or those more exposed to extreme weather can lose significant value in some scenarios for climate change. However, these hidden risks are currently barely reflected in collateral valuation practices. Real estate or other fixed asset collateral behind corporate loans can also face a steep revaluation (drop in value), as their use can rapidly or prematurely become impossible due to their high GHG emissions and carbon dependence. A huge part of literature deals with these socalled "stranded assets", which include fossil fuel mines and stocks, the plant units using them, and large production machines (Caldecott et al. 2014; Weyzig et al. 2014). Issues of collateral valuation affect LGD calculations to a great extent.

"Stranded assets" are also present in the securities markets, so they cannot be ignored in terms of securities collateral and exposures in the banks' trading books. Market risk includes the revaluation risk (exchange rate movement) of just these positions, including not only securities but also foreign currencies and commodities. According to the frequently cited "carbon bubble" problem, the market has typically not yet priced in the risks of climate change and the associated risks of socioeconomic transition for these instruments. Thus many of the assets involved are currently overvalued. However, upon investor recognition, the bubble may burst (Weyzig et al. 2014; Griffin et al. 2015). Market risk models are most often based on forecast cash flows, therefore, changes related to climate change may primarily require a revision of cash flow forecasts (see, for example, Hayne et al. 2019). From among the wide range of operational risks, it is worth highlighting the legal and reputational risks - especially the so-called liability risk, which may pass onto the credit institution mainly due to the financing of polluting economic activities in breach of environmental standards. However, the possibility of quantifying such risks is limited. 
According to Figure 3, in addition to the individual key risk models, it is also necessary to take stock of bank profitability, which the specific projection of the stocks and flows of banking operations can rely on $(2 c)$. Such correlations should be available, at least in the form of assumptions and strategic targets, for the development of bank pricing (interest margins, fees and commissions), trading profit, operating cost ratio, etc. In these cases, climate change as a framework prevails in two main ways. On the one hand, a significant part is based on some outcome pathways of the macroeconomic model that processes climate scenarios (e.g. yield curves). On the other hand, a credit institution may modify "normal" assumptions (e.g. project a higher cost ratio due to the drastic transition as a result of the increasing resource requirements for managing bad loans).

\subsection{Bank reports (financial statements)}

With the full set of tools, the credit institution's various financial items are systematically converted in each scenario to the individual points of time/periods of the analysis horizon (2c). This requires reports and statements corresponding to the cut-off date (balance sheet, income statement, analytics, etc.). In the case of credit exposures, credit losses (CL) are calculated using the PD and LGD models developed in the previous step. The revaluation of items carrying market risk also contributes to quantifying the impacts on profitability and determining future exposure values. By applying the appropriate weights, the development of the bank's risk-weighted assets (RWA) can be forecast, which is also a condition for the provision of capital adequacy (capital adequacy ratio) (3).

In all this, the crucial issue is the assumption concerning a change in the balance sheet total. In the shorter term, it may be acceptable to consider the balance sheet total unchanged (the so-called gross static balance sheet assumption). ${ }^{15}$ However, this leads to less realistic results as it does not allow for adaptation to the scenario (Resti 2018). Climate stress tests, especially over a longer time horizon, should contain certain dynamic elements, which allow for the bank to assess and select clients based on their vulnerabilities and climate actions. It can be a kind of simple sensitivity analysis that reveals the consequences of giving priority to clients with a better environmental performance under a given scenario.

\subsection{Capital adequacy as an outcome and consideration of spill-over effects}

As already stated, the purpose of climate stress tests is to assess the development of credit institution profitability and, in this context, capital adequacy in each scenario (Figure 3, 3). The most advanced stress tests may even be able to assess spillovers and "contagions" (4) in the banking system. (A possible modelling approach is

\footnotetext{
${ }^{15}$ Accordingly, bank assets and liabilities that mature within the time horizon of the stress test are replaced at maturity by items of the same type, currency, maturity and credit quality. As a result, not only the size but also the composition of the balance sheet total remains unchanged (Resti 2018).
} 
presented by Haldane - May 2011). The second-round impacts may also include real economic feedback: if a climate-neutral transition brings about an economic downturn and a substantial increase in non-performing loans in the shorter term, banks may stop lending as a response (in an overall sense or to certain industries).

\section{Conclusions}

The essay reviewed the basic issues, possible structure, and main challenges of credit institution climate stress tests with the aim of outlining a comprehensive framework for performing bank climate stress tests in Hungary for stakeholders (market players, macro- and micro-prudential policy).

Climate change can entail significant temperature rises and thus environmental damage (physical risk). To prevent this, humanity must significantly reduce its GHG emissions and put the economy on a carbon-neutral path through technological change and economic policy intervention (transition risk) to reach the Paris climate target of less than $+2^{\circ} \mathrm{C}$. These processes primarily affect credit institutions through their clients, i.e. the financed actors. Identifying vulnerabilities is important for prudent operation and compliance with related recommendations, but it also poses a major challenge for banks. The level of uncertainty is much higher than "normal", mainly due to the lack of historical data as well as the lengthy time horizon and many interactions of the unfolding climate change. There are basically two options for risk measurement: identifying one or a few specific shocks and examining the direct, shorter-term (3-5 years) adaptation of the economy, or a long-term analysis of weather events and the complex dynamics of the decarbonisation process. The former is closer to "normal" bank stress tests and easier to manage with its existing toolbox. The latter, which can also provide the bank with a much more comprehensive picture for strategy-making, holds many more challenges that are still subject to intense thinking among the world's financial institutions.

The general structure of stress tests can be relevant over both time horizons. The analysis starts from scenarios of exogenous shocks attributable to climate change. Defining scenarios and identifying mechanisms of action are probably the biggest task of climate stress testing. The shocks and the pathways of key factors must be given in a way to enable the macroeconomic model to incorporate and process them. The description of real economic and macro-financial impacts therefore requires that the scenarios and the macro-model be selected together, both interlinked. To this end, especially in the case of long-term complex analysis, involving external experts may be unavoidable. In analytical practice, there are several signs that statistical-econometric models relying on empirical behavioural equations are most suitable for climate stress tests. Such models should include the interlinkages and interactions of the atmosphere and the environment, 
energy consumption and the economy. Another important requirement for the macroeconomic model is the industrial breakdown and the realistic management of the financial system, the production of some systemic financial variables. The outcome pathways of the macroeconomic model should be tailored to the needs of the risk models underlying the individual banking calculations. Addressing several specific issues of climate shocks and "fine-tuning" the effects is only possible by reconsidering the existing risk models, correlations and assumptions. This phase represents the other key challenge for climate stress testing. Questions need to be answered on how actors within a sector differ regarding their PD emission and strategies, or how to take into account the risks inherent in pricing "stranded assets". In possession of the appropriate models, correlations and assumptions, the main financial items of the credit institution are systematically re-calculated at different points/sections of the time horizon in each scenario. In this phase, the main issue is how to relax the gross static balance sheet assumption. By overcoming all of these challenges, the credit institution arrives at the main outcome, the expected pathways of profitability and capital adequacy under each scenario. The analysis can be further completed by mapping the impacts on the financial system and macroeconomic spillovers arising from the bank's position (feedback). The overall conclusion of the process is that the building blocks are closely related and can only be "optimised" in the light of the analysis as a whole.

Solving any of the challenges means, with a little exaggeration, reviewing a library's worth of literature and requires many working hours. However, the preliminary review and establishment of the framework simplifies the work of credit institutions markedly, serves as a compass, and ultimately, is more important than the details. Simpler assumptions can also be explicitly useful if they are clear and their impact on the results can be traced. Carrying out climate stress tests as soon as possible is in the interest of banks, central banks and supervisory authorities, and even a wide range of economic actors, not only to address vulnerabilities but also to seize the opportunities offered by decarbonisation.

\section{References}

$2^{\circ}$ Investing Initiative (2018): $2^{\circ}$ Scenario Analysis. Background Information on the "Paris Agreement Capital Transition Assessment" (PACTA) Scenario Analysis Tool. https://www. transitionmonitor.com/wp-content/uploads/2018/08/Scenario-Analysis-BackgroundInformation.pdf. Downloaded: 2 April 2020.

Allen, T. - Dees, S. - Boissinot, J. - Caicedo Graciano, C.M. - Chouard, V. - Clerc, L. - de Gaye, A. - Devulder, A. - Diot, S. - Lisack, N. - Pegoraro, F. - Rabaté, M. - Svartzman, R. - Vernet, L. (2020): Climate-Related Scenarios for Financial Stability Assessment: an Application to France. Working Paper, No. 774, Banque de France, July. https://doi.org/10.2139/ ssrn.3653131 
Battiston, S. - Mandel, A. - Monasterolo, I. - Schütze, F. - Visentin, G. (2017): A Climate Stress-Test of the Financial System. Nature Climate Change, 7: 283-288. https://doi. org/10.1038/nclimate3255

Battiston, S. - Monasterolo, I. (2019): A Climate Risk Assessment of Sovereign Bonds' Portfolio. Paper, WU Vienna University of Economics and Business. https://epub.wu.ac. at/7261/. Downloaded: 19 March 2020.

BlackRock (2015): The Price of Climate Change. Global Warming's Impact on Portfolios. https://www.blackrock.com/corporate/literature/whitepaper/bii-pricing-climate-riskinternational.pdf. Downloaded: 7 January 2019.

Blanchard, O. (2018): On the Future of Macroeconomic Models. Oxford Review of Economic Policy, 34(1-2): 43-54. https://doi.org/10.1093/oxrep/grx045

BoE (2018): Transition in Thinking: The Impact of Climate Change on the UK Banking Sector. Prudential Regulation Authority, Bank of England, September. https://www.bankofengland. co.uk/-/media/boe/files/prudential-regulation/report/transition-in-thinking-the-impactof-climate-change-on-the-uk-banking-sector.pdf. Downloaded: 20 November 2018.

BoE (2019): The 2021 Biennial Exploratory Scenario on the Financial Risks from Climate Change. Discussion Paper, Bank of England, December. https://www.bankofengland.co.uk/ paper/2019/biennial-exploratory-scenario-climate-change-discussion-paper. Downloaded: 8 January 2020.

Borio, C. - Drehmann, M. - Tsatsaronis, K. (2014): Stress-Testing Macro Stress Testing: Does it Live up to Expectations? Journal of Financial Stability, 12(June): 3-15. https://doi. org/10.1016/j.jfs.2013.06.001

Burke, M. - Hsiang, S.M. - Miguel, E. (2015): Global Non-Linear Effect of Temperature on Economic Production. Nature 527: 235-239. https://doi.org/10.1038/nature15725

Caldecott, B. - Tilbury, J. - Carey, C. (2014): Stranded Assets and Scenarios. Discussion Paper, Smith School of Enterprise and the Environment, University of Oxford.

Cambridge Econometrics (2019): E3ME Technical Manual v6.1. https://www.e3me.com/ wp-content/uploads/2019/09/E3ME-Technical-Manual-v6.1-onlineSML.pdf. Downloaded: 31 March 2020.

Di Silvestre, M. L. - Favuzza, S. - Sanseverino, E. R. - Zizzo, G. (2018): How Decarbonization, Digitalization and Decentralization Are Changing Key Power Infrastructures. Renewable and Sustainable Energy Reviews, 93(October): 483-498. https://doi.org/10.1016/j. rser.2018.05.068 
ESRB (2016): Too Late, Too Sudden: Transition to a Low-Carbon Economy and Systemic Risk. Reports of the Advisory Scientific Committee, No. 6, European Systemic Risk Board. https:// www.esrb.europa.eu/pub/pdf/asc/Reports_ASC_6_1602.pdf. Downloaded: 15 January 2019.

Farmer, J.D. - Hepburn, C. - Mealy, P. - Teytelboym, A. (2015): A Third Wave in the Economics of Climate Change. Environmental and Resource Economics, 62(2): 329-357. https://doi. org/10.1007/s10640-015-9965-2

Feyen, E. - Utz, R. - Huertas, I. Z. - Bogdan, O. - Moon, J. (2020): Macro-Financial Aspects of Climate Change. Policy Research Working Paper, No. 9109, World Bank Group. https:// doi.org/10.1596/1813-9450-9109

FSB-TCFD (2017): Recommendations of the Task Force on Climate-Related Financial Disclosures. Final Report. Financial Stability Board - Task Force of Climate-Related Financial Disclosures, June. https://www.fsb-tcfd.org/wp-content/uploads/2017/06/FINAL-TCFDReport-062817.pdf. Downloaded: 14 April 2020.

Gallic, E. - Vermandel, G. (2019): Weather Shocks. HAL Archive Ouverte en Sciences de l'Homme et de la Société, 13 May. https://halshs.archives-ouvertes.fr/halshs-02127846. Downloaded: 18 March 2020.

Griffin, P. A. - Myers Jaffe, A. - Lont, D.H. - Dominguez-Faus, R. (2015): Science and the Stock Market: Investors' Recognition of Unburnable Carbon. Energy Economics, 52: 1-12. https://doi.org/10.1016/j.eneco.2015.08.028

Haldane, A.G. - May, R.M. (2011): Systemic Risk in Banking Ecosystems. Nature, 469(January): 351-353. https://doi.org/10.1038/nature09659

Harari, Y.N. (2015): Sapiens. Az emberiség rövid története (A Brief History of Humankind). Animus Kiadó, Budapest.

Hare, B. - Brecha, R. - Schaeffer, M. (2018): Integrated Assessment Models: What Are They and How They Arrive at Their Conclusions? Climate Analytics, October. https:// climateanalytics.org/media/climate_analytics_iams_briefing_oct2018.pdf. Downloaded: 20 April 2020.

Hayne, M. - Ralite, S. - Thomä, J. - Koopman, D. (2019): Factoring Transition Risks into Regulatory Stress-Tests: The Case for a Standardized Framework for Climate Stress Testing and Measuring Impact Tolerance to Late \& Sudden Economic Decarbonization. $2^{\circ}$ Investing Initiative. EBA $8^{\text {th }}$ Policy Research Workshop, European Banking Authority, 27-28 November. https://doi.org/10.35944/jofrp.2019.8.1.013

Henry, J. - Kok, C. (ed.) (2013): A Macro Stress Testing Framework for Assessing Systemic Risks in the Banking Sector. ECB Occasional Paper Series, No. 152, European Central Bank. https://www.ecb.europa.eu/pub/pdf/scpops/ecbocp152.pdf 
Horváth, L. (2003): A post-keynesi szemlélet és elosztáselméleti alkalmazása (Application of the post-Keynesian approach and distribution theory). PhD dissertation, Department of Macroeconomics, Budapest University of Economic Sciences and Public Administration.

IPCC (2013): Climate Change 2013. The Physical Science Basis. Intergovernmental Panel on Climate Change, Working Group 1, Contribution to the Fifth Assessment Report of the IPCC. Cambridge University Press, Cambridge, United Kingdom and New York, NY, USA.

ITM (2020): Nemzeti Energia- és Klímaterv (National Energy and Climate Plan). Innovációs és Technológiai Minisztérium (Ministry of Innovation and Technology), Hungary. https://ec.europa.eu/energy/sites/ener/files/documents/hu_final_necp_main_hu.pdf. Downloaded: 14 April 2020.

Marshall, G. (2014): Don't Even Think About It. Why Our Brains Are Wired to Ignore Climate Change. Bloomsbury USA, New York.

MNB (2019): Green Finance in Hungary. Consultation document, Magyar Nemzeti Bank, 3 July. https://www.mnb.hu/letoltes/green-finance-in-hungary-consultation-paper.pdf. Downloaded: 14 April 2020.

NGFS (2019): A Call for Action. Climate Change as a Source of Financial Risk. First Comprehensive Report, Central Banks and Supervisors Network for Greening the Financial System, April. https://www.ngfs.net/sites/default/files/medias/documents/ngfs_first_ comprehensive_report_-_17042019_0.pdf. Downloaded: 16 April 2020.

Pollitt, H. - Mercure, J.-F. (2018): The Role of Money and the Financial Sector in EnergyEconomy Models Used for Assessing Climate and Energy Policy. Climate Policy, 18(2): 184-197. https://doi.org/10.1080/14693062.2016.1277685

Quagliariello, M. (ed.) (2009): Stress-Testing the Banking System. Methodologies and Applications. Cambridge University Press, Cambridge. https://doi.org/10.1017/ CBO9780511635618

Resti, A. (2018): How Demanding and Consistent Is the 2018 Stress Test Design in Comparison to Previous Exercises? Banking Union Scrutiny, In-Depth Analysis Requested by the ECON Committee, European Parliament, June. https://www.europarl.europa.eu/RegData/ etudes/IDAN/2018/614511/IPOL_IDA(2018)614511_EN.pdf. Downloaded: 23 April 2020.

Rudebusch, G.D. (2019): Climate Change and the Federal Reserve. FRBSF Economic Letter, 2019-9, Federal Reserve Bank of San Francisco. https://www.frbsf.org/economic-research/ files/el2019-09.pdf. Downloaded: 2 April 2020.

Staden, C. van (2020): COVID-19 and the Crisis of National Development. Nature Human Behaviour, 4: 443-444. https://doi.org/10.1038/s41562-020-0852-7 
Stamate, A. - Tatarici, L. (2019): Climate Risks. Implications for the Financial Sector. National Bank of Romania, $13^{\text {th }}$ Edition of the Seminar on Financial Stability Issues, Bucharest, 13 September. https://www.bnr.ro/DocumentInformation. aspx?idDocument=32455\&directLink=1. Downloaded: 6 January 2020.

Taleb, N.N. (2007): The Black Swan: The Impact of the Highly Improbable. Penguin Random House, New York.

UN (2015): Paris Agreement. United Nations Framework Convention on Climate Change, 12 December. https://unfccc.int/files/meetings/paris_nov_2015/application/pdf/paris_ agreement_english_.pdf. Downloaded: 2 April 2020.

UNEPFI (2018a): Navigating a New Climate. United Nations Environment - Financial Initiative \& Acclimatise Group Ltd. https://www.unepfi.org/publications/banking-publications/ navigating-a-new-climate-assessing-credit-risk-and-opportunity-in-a-changing-climate/. Downloaded: 8 August 2018.

UNEPFI (2018b): Extending our Horizons. United Nations Environment - Financial Initiative \& Oliver Wyman. https://www.unepfi.org/wordpress/wp-content/uploads/2018/04/ EXTENDING-OUR-HORIZONS.pdf. Downloaded: 8 August 2018.

Vermeulen, R. - Schets, E. - Lohuis, M. - Kölbl, B. - Jansen, D.-J. - Heeringa, W. (2018): An Energy Transition Risk Stress Test for the Financial System of the Netherlands. Occasional Studies, Vol. 16/7, De Nederlandsche Bank.

Walter, Gy. (2016): Kereskedelmi banki ismeretek (Commercial banking knowledge). Alinea Kiadó, Budapest.

Weyzig, F. - Kuepper, B. - Gelder, J.W. van - Tilburg, R. van (2014): The Price of Doing Too Little Too Late. The Impact of the Carbon Bubble on the EU Financial System. A report prepared for the Greens/EFA Group - European Parliament. Green New Deal Series, Vol. 11, February. https://gef.eu/wp-content/uploads/2017/01/The_Price_of_Doing_Too_ Little_Too_Late_.pdf. Downloaded: 3 January 2019. 